\title{
Editorial
}

\section{Developing communication skills}

Public relation is a very vital part of the art of practicing medicine. One needs to develop good communication skills in order to understand the patient's history, making a correct diagnosis, interpret data and deliver quality treatment. Not everyone is a skilled communicator although man himself has been described as compulsive communicator by David attenborough ${ }^{1}$. Language and communication is not a monopoly of the human race. Excellent communication exists in the animal and insect world and it is hardly or not all understood by humans. I would like to examine some of the basic needs for developing communications skills in medical practice.

\section{In medical education}

Medical schools in Canada and Australia have incorporated examination in communication as an essential part of the curriculum for undergraduates. It is compulsory for students to develop communication skills in order to obtain a medical degree. This has come about after many years of observation that doctors are poor communicators. It has also become necessary to incorporate this as a compulsory subject because of a high degree of awareness of medical treatment by the general public. The availability of information via the media such as newspapers, magazines, television and now the internet has provided wide spread and detailed knowledge of available treatment options for every and any ailment. Educated patients seek answers to their problems from such a vast source. As a result the newly graduated medical student may find himself deficient in information when dealing with patients. It is therefore essential that the undergraduate understands the importance of communication skills as a doctor. This is true of post graduate education as well. Specialization in various medical fields changes one's outlook towards a patient. It is important that they do not lose sight of the fact that the patient is not an organ or a specialized system but must be treated as a whole. The inclusion of effective communication in the curriculum of post graduate and super specialty trainee is equally important.

\section{In Practice}

It is a common complaint from patients that a doctor has either not communicated the diagnosis or the treatment options available for a particular disorder. As a result litigation against doctors and hospitals have become rampant, particularly in the developed countries. The introduction of the consumer protection act and the inclusion of all medical professionals under this act in India has now made it mandatory that one develop good communication skills to avoid misunderstanding and litigation. Open, honest and direct communication with the patient or his relative on the diagnosis, the treatment options and recommendation of the best option for a particular patient should be a basic fundamental requirement to improve the quality of medical care. It is the absence of such honest and direct communication that usually leads to dissatisfied patients who seek justice through litigation.

\section{In administration}

Doctors in administrative positions and heads of departments have little or no formal training in administration. The basics of good administration are understanding, fairness, respect and open discussion. They must learn the art of colleague treatment. A department reaches glorious heights if the head of the department is a reasonable and wise man. He/she must learn to communicate effectively by appreciating the good in his colleagues and encouraging individual and team efforts. He/she must keep open all avenues for communication at all times. $\mathrm{He} /$ she must pass on the benefits and share the good with his colleagues. This will generate respect for the head of the department with colleagues and allow rapid and healthy progress in the department. In the absence of good inter personal communication, relations sour. The department then becomes a disjointed, fragmented attempt by individuals for their own personal benefits to the detriment of the profession and institution.

\section{In the media}

Effective communication is also vital with the media. One must be honest enough to communicate the truth and the correct information which will benefit the reader of the newspaper or the viewer of the television programme. Self aggrandizement is best avoided. Newspapers have reported dubious observations which are communicated through a press which does not appear to be responsible in informing the truth. Correspondents rarely if ever research the veracity of statements made by doctors. The responsibility therefore 
lies with the doctor. The general public perceive information obtained from such reports as gospel truth and seek a remedy that may not be correct for them. Professional associations periodically publish ethical conduct rules for their members regarding relationship with the media.

\section{In scientific presentation}

Scientific communication has been refined to an art form. Organisers of every conference and editors of every journal issue instructions to the participating members on how to write an abstract or a manuscript. Clear and concise instructions take the concerned writer through a series of steps for coherent and correct communication of their knowledge. Presenting papers at a conference requires considerable thought and ability. Ability can be acquired by attending conferences and listening to good speakers. One can observe different methods of presentation. The use of slides is a very good method of communicating one's thoughts. However, slides must attract the reader's attention and must contain important but brief information, to sustain the interest of the audience. Elaborate slides filled with information make the audience lose interest in the presentation. In order to be able to speak with authority one must have a deep and thorough knowledge of the subject or extensive experience in the area. It is then that the facts flow in a fluent manner and communication of such information becomes easy.

Similarly in submitting a manuscript it is necessary to go through four to six drafts. At each step one must go back and read the instructions to authors carefully and ensure complete adherence to the instructions. Over period of time and with practice manuscripts become more and more acceptable to journals. This does not happen by magic but comes about by hard work and with the development of skills in effective communication.

\section{In speaking \& writing}

There is an enormous difference between verbal and written communication. A new born child will communicate instantly by crying. Verbal communication requires ability to pay attention to what is being said and to interpret the same in the context of the situation. The essence of good verbal communication is the development of a good vocabulary in that language. Again verbal communication can be taught and can be learned throughout one's life. The adage "it is better to keep your mouth shut and be thought of fool than to open it and remove all doubt" is a good starting point for someone who wishes to develop reasonably good skills in verbal communication. They should learn to listen first. On the other hand written communication requires one to follow a certain format. All of these formats, for example, writing to a father, sister, brother, colleague, boss, wife and to express one's emotions in the event of life's situation like death, birth, marriage etc. have all been well documented. Official communication and legal communication requires the use of a particular type of language. Similarly communication of medical information requires developing the skills to adjust to the reader who may be a lay person or a specialist professional colleague. One must also have a reasonable appreciation of the level of education and understanding of the audience before preparing a manuscript. Again all of these are skills that can be easily learned by everyone. The purpose of this editorial is urge you to develop these particular skills both in verbal and written communication of professional knowledge. I would urge you to take every opportunity to present your observations at conferences and publish them as manuscripts, in the process developing your own skills in communication.

"For oft the apparel proclaims the man" said Shakespere. While appearance may be gentle, speech becomes the second most important attitude be wear. Proper communication requires the acquisition of simple but easily learned skills. This is especially so in dealing with human subjects. Let the other man believe that he has met someone with whom he has had the most comfortable and the enjoyable conversation. This one important step will regain respect for a noble profession that seems to be deteriorating on a daily basis.

\section{References}

1. Life on Earth. Ed. David attenborough, Collins/BBC, Reader's Digest Association Ltd. 1980. 